\title{
A ocupação de São Paulo: inscrições urbanas como elos ou barreiras entre centro e periferia
}

\author{
São Paulo's occupation: urban inscriptions as links or barriers between \\ downtown and outskirts
}

http://dx.doi.org/10.5007/2178-4582.2016v50n1p166

\author{
Rafael Giardini Lenzi \\ Pontifícia Universidade Católica de São Paulo/SP, Brasil
}

Mariana Cortez

Universidade Federal da Integração Latino-Americana, Foz do Iguaçu/PR, Brasil

A cidade de São Paulo é um cenário privilegiado da arte urbana, especialmente por meio da visualidade das inscrições urbanas. Entendemos o artista da rua como um agente social e um destinador que atua e transforma a paisagem urbana, e sua arte como forma de democratização da expressão plástica. À luz da Sociossemiótica desenvolvida por Landowski, analisamos a pichação e o grafite - práticas que entrelaçam centro e periferia, investindo sujeitos diferenciados dos programados pela cidade. Diante da diversidade artística em São Paulo, interessa descrever como essas inscrições urbanas ocupam a cidade e delineiam sujeitos submetidos a destinadores outros na urbe. Utilizamos, então, uma diferenciação do praticante (artista) e da prática (sua arte) para entender essa forma de ocupação urbana como elo entre as polaridades sócio-espaciais da cidade.

Palavras-chave: Inscrições Urbanas; Centro-Periferia; São Paulo; Destinadores; Visualidade.
São Paulo is a privileged scene to urban art, especially through the visuality of urban inscriptions. We assume the street artist as a social agent and an addresser that acts and changes urban landscape, and their art as a democratization of plastic expression. Under social semiotics theory, developed by Landowski, we analyze wall writings and graffiti - practices that intertwine central and peripheral areas, investing distinct individuals from the ones programmed by the city. Given the artistic diversity in São Paulo, it is interesting to describe how these urban inscriptions occupy the city and delineate subjects that are subdued to other addressees of the city. Therefore we apply a distinction between the practitioner (the artist) and the practice (the art) in order to understand this kind of urban occupation as a bond that connects the city's social and spatial polarities.

Keywords: Urban Inscriptions; Downtown-Outskirts; São Paulo; Addressers; Visuality.

\section{Contextualizando a metrópole paulista}

"Para descobrir quanta escuridão existe em torno, é preciso concentrar o olhar nas luzes fracas e distantes." (Ítalo Calvino)

A obra Brás, Bexiga e Barra Funda, de Alcântara Machado (1999), apresenta a formação da sociedade paulistana da seguinte maneira:

Durante muito tempo a nacionalidade viveu da mescla de três raças que os poetas xingaram de tristes: as três raças tristes. A primeira, as caravelas descobridoras encontraram aqui comen- 
do gente e desdenhosa de "mostrar suas vergonhas". A segunda veio nas caravelas. Logo os machos sacudidos desta se enamoraram das moças "bem gentis" daquela, que tinham cabelos "mui pretos, compridos pelas espadoas". E nasceram os primeiros mamalucos. A terceira veio nos porões dos navios negreiros trabalhar o solo e servir a gente. Trazendo outras moças gentis, mucamas, mucambas, munibandas, macumas. E nasceram os segundos mamalucos. E os mamalucos das duas fornadas deram o empurrão inicial no Brasil. O colosso começou a rolar.

Neste artigo de fundo, Machado se refere aos índios, aos brancos (portugueses) e aos negros, mas do decorrer de sua narrativa a presença do migrante italiano será o foco, então ele complementa o artigo de fundo inserindo a chamada "gente alegre" que veio trabalhar o solo e também misturar-se à gente "local", formando o que ele chama de uma "nova fornada" de brasileiros.

Assim desenham-se "as gentes" da cidade e suas implicações geográficas de ocupação do espaço. Na virada no século XX, chegam a São Paulo os migrantes. A cidade tinha nesta época 240.000 habitantes. Antigas chácaras ao redor do núcleo histórico da cidade foram loteadas e a área urbana expandiase continuamente. Ferrovias faziam ligação com o interior, onde se produzia o café e chegavam até Santos, por onde ele seria exportado. Este corredor do café (interior-litoral) fez da cidade de São Paulo o espaço ideal de comércio e daí surge a cidade próspera.

Na passagem do século XIX ao XX a cidade já estava transformandose muito rapidamente. $\mathrm{O}$ comércio começava a diversificar-se, atraindo todo tipo de atividades. Foi no início do século XX que São Paulo começou a industrializar-se. Com isso a população começou a aumentar, principalmente com a vinda de migrantes estrangeiros, em sua maioria italianos, espanhóis, sírio-libaneses, japoneses e judeus. Ainda hoje é fácil comprovar a vinda destes migrantes, pois na cidade há bairros que guardam marcas desta imigração - como o bairro da Liberdade - dos japoneses; Higienópolis e Bom Retiro dos judeus, e Bixiga - dos italianos.

Este rápido crescimento populacional, que tentamos demonstrar com dados e descrição, implicou desordem. A cidade foi expandindo-se, mas sem o planejamento necessário, este espraiamento para além dos rios (Tietê e Pinheiros) foi gerando problemas importantes para a cidade. Problemas entendidos como carências de transporte, habitação, saúde, lazer entre outros. As periferias foram surgindo também com o chamado êxodo rural: a partir dos anos 30 e 40 . As pessoas começaram a migrar do campo e a cidade ia recebendo as pessoas, e essas se acomodavam como podiam, formando as favelas, os cortiços, ou seja, a marginalização dos espaços, suas zonas opacas 
como sugere Milton Santos (2010). Segundo o geógrafo, na cidade "luminosa", moderna, a naturalidade do objeto técnico criaria uma mecânica rotineira, um sistema de gestos sem surpresa. Essa historização geraria no organismo urbano áreas constituídas ao sabor da modernidade que se justaporiam, superporiam e contraporiam em relação ao resto da cidade onde vivem os pobres, nas zonas urbanas "opacas". Estas seriam espaços aproximativos e de criatividade. $\mathrm{O}$ autor ainda afirma que os espaços inorgânicos é que são abertos, e que os espaços regulares são fechados, racionalizados e racionalizadores. (SANTOS, 2010, p. 595)

O mapa de São Paulo mostra os bairros centrais cercados pelos rios-Tietê e Pinheiros - que também sofreram muito com a expansão da cidade e estão comprimidos por suas marginais (Figura 1). São Paulo tem como problema - e esse em particular interessa ao artigo que se apresenta - uma constituição espraiada, quer dizer, dispersa, mas apesar disso, continua dependente do centro. Centro e periferia estão isolados e cada um cumpre seu papel, bem como o descreve Santos (2010).

Figura 1: Mapa Centro-Periferia

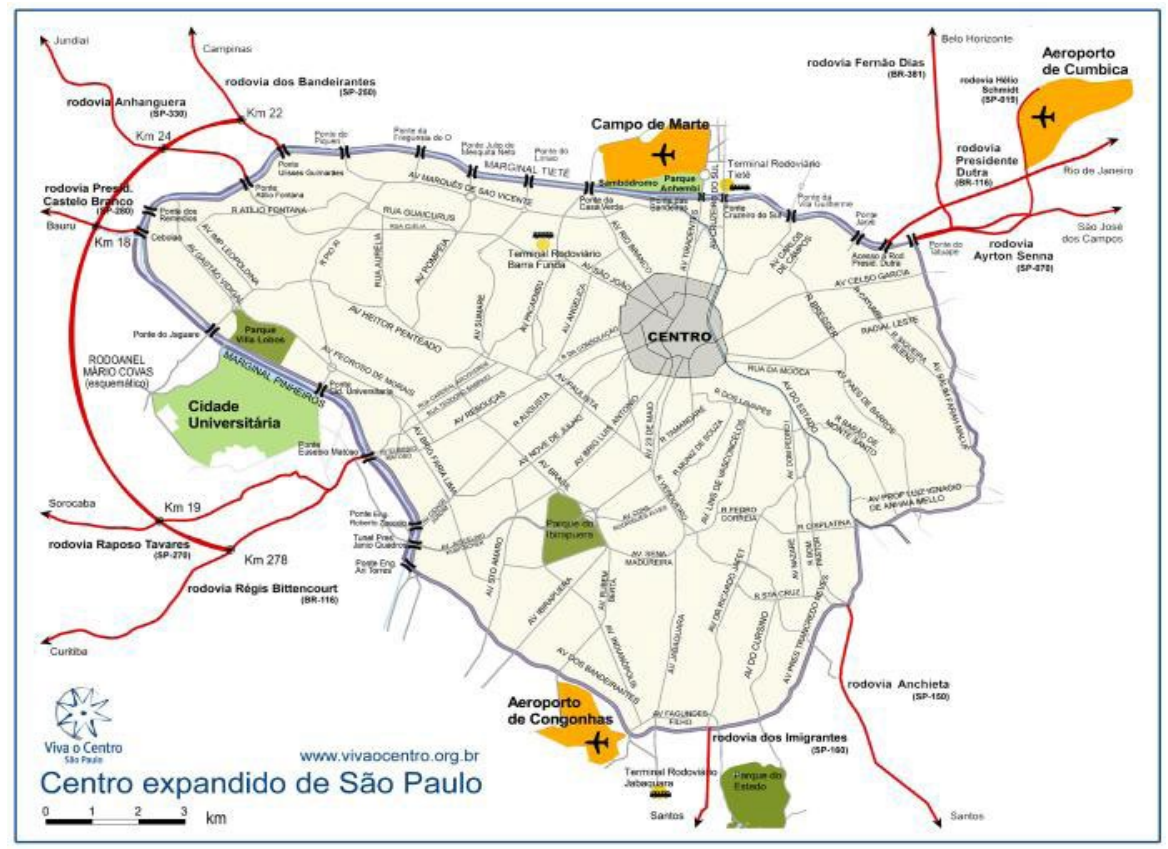

Fonte: Associação Viva o Centro (c2013).Disponível em: http://www.vivaocentro.org.br/ curta-o-centro/como-chegar-ao-centro.aspx. 
O centro abriga o "centro financeiro e comercial" da cidade, oferece vagas de empregos, além do lazer que está totalmente centralizado, e o cidadão que está na periferia, além-rios, deve sair de lá para trabalhar, tratar-se, divertirse. $\mathrm{O}$ centro da cidade, portanto, é bem diferente dos bairros periféricos. $\mathrm{E}$ evidentemente isso gera tensão. Esta tensão centro-periferia estará bastante marcada na produção cultural proveniente dos bairros afastados do centro, especialmente em relação às inscrições impressas na cidade.

Pretendemos demonstrar em nossas análises das inscrições urbanas (grafite e pichação) na cidade de São Paulo as vozes das práticas sociais que a ocupam e como seus sujeitos se apoderam dos espaços urbanos, sejam eles autorizados ou não pelo espaço oficial e regulamentado pela cidade.

\section{As inscrições urbanas desenhando espaços entre a periferia e o centro}

A arte grafite surgiu como forma de protesto e um espaço marcado pela tensão entre o permitido e o proibido na paisagem da cidade. Jovens revolucionários, no final dos anos 1960, apropriaram-se dos muros da cidade de Paris para inserir e dar visibilidade às vozes abafadas em outras mídias. Vozes essas, normalmente, carregadas de paixões.

Decorrente desta origem, a arte grafite é automaticamente vinculada à atmosfera marginal. De 1960, nas ruas de Paris, ao grande boom nos anos 1980, em Nova York, essa arte urbana vem conquistando territórios e legitimando-se. De sujeitos perseguidos pela polícia, os artistas do grafite ganham prestígio, sem, contudo, negar a importância da rua, dos muros, dos desenhos arquitetônicos da cidade que são, para esses artistas, os suportes de sua arte.

Com o passar do tempo, as escrituras de protestos iniciais foram cedendo espaço aos discursos verbo-visuais mais elaborados, cuidados, em que se identificam traços de estilo e diálogo com outras artes. Os artistas urbanos começaram a impregnar suas produções com um estilo pessoal que vai de uma determinada maneira de registar o nome $\left(\right.$ Tag $\left._{\text {Reto }}{ }^{l}\right)$ à criação de personagens ou cenas pictóricas que remontam às práticas sociais vividas em outros momentos na cidade, como os grafites de Eduardo Kobra (KOBRA) em seu projeto "Muros da memória"2.

\footnotetext{
1 "Tag Reto é um termo que deriva da denominação utilizada pelos grafiteiros e tem origem em Nova York, e quer dizer assinatura. O tag reto foi difundido pelos 'pichadores' de São Paulo e é mais que uma assinatura, já se tornou um estilo de letra. Surgiu como elemento diferenciador dos grupos de 'pichadores' que foram buscando desenhos próprios para as letras. Esse estilo de letra é caracterizado por letras retas, alongadas e pontiagudas, que procuram ocupar o maior espaço possível no suporte, o surgimento deste estilo de letras típico de São Paulo é único no mundo" (PICHAÇÃO).

2 Vale sinalizar que este trabalho não diferencia grafite e pichação, mas antes propõe o debate, já que este vai ser também um embate na cidade de São Paulo.
} 
Apesar das transformações dessa prática, o diálogo palavra-imagem permanece, manifestando quase sempre uma denúncia: seja de um espaço cinza que necessita cor, seja o protesto sobre a violência policial na grande metrópole. Neste contexto, a dupla "Os Gemeos" foi uma das responsáveis em São Paulo por dar visibilidade ao grafite da cidade e reconhecimento nacional e internacional.

Figura 2: Os gemeos - Recado à Prefeitura

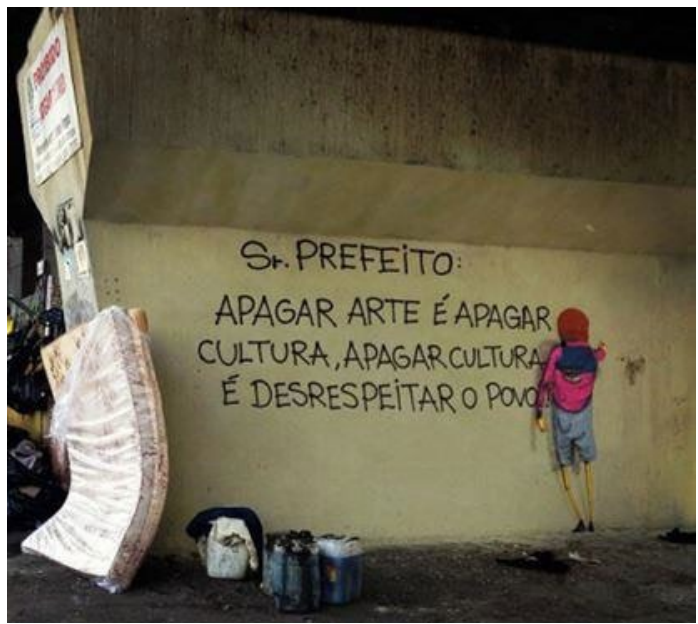

Fonte: OS GEMEOS protestam contra prefeitura de SP após grafite apagado. Portal Rua Augusta, São Paulo, 2013. Disponível em: http://augustasp.com/ruaaugusta/05/osgemeos-protestam-contra-prefeitura-de-sp-apos-grafite-apagado/

Nesta imagem, os artistas urbanos protestam por meio de um diálogo com a prefeitura da cidade. Dirigem-se especificamente ao governante para que ele reconheça e valorize a arte de rua da cidade de São Paulo. Aqui as vozes silenciadas investem-se, por meio de sua arte, para fazer ver à autoridade, a importância do grafite. Nota-se que estão presentes as duas vertentes da pintura de rua: no discurso verbal - a pichação, e no desenho - o grafite, que compreende a inscrição e a figura de um personagem em uma cena metalinguística, já que o personagem representa o próprio artista. Deste conjunto depreende-se a ligação da prática ao gesto, com o estabelecimento visual desse sujeito que picha e grafita. Nessa relação com o gesto, de acordo com Borges (1984, p. 65), "a curta duração dos graffiti só poderá comprovar que seu maior valor encontra-se em seu gesto (e não em sua linguagem)". O diálogo proposto pelo grafite indica uma mudança de posição do sujeito, antes oprimido e caçado pelas autoridades e agora um sujeito que se dirige diretamente ao governo, estabelecendo uma relação mais igualitária, e por isso afirmamos que existe um certo apoderamento da cidade pelo sujeito marginalizado. 
Para Certeau (2004), ao caminharmos pela cidade vamos compondo nossa enunciação pedestre que se apropria do sistema urbano, conectando, articulando e misturando os modos de operar táticos e estratégicos conforme as relações que estabelecemos com o mundo. Os passos distraídos do transeunte mobilizam suas experiências afetivas e sensoriais, lembranças e encontros, constituindo os territórios físicos e as referências simbólicas, e vão dessa maneira, em sua memória, contextualizando os espaços em narrativas. Os autores das inscrições urbanas contribuem também para criar novas narrativas na cidade; por meio de seus pixos, tags, grafites, conduzem os usuários da metrópole por um passeio em inúmeras aventuras, protestos, divagações, reivindicações.

Em São Paulo, as inscrições urbanas estabelecem uma relação bastante complexa, tendendo a haver uma cisão entre pichação e grafite. Enquanto em outras cidades do mundo o que predomina é que a pichação seria apenas um estilo dentro do grafite, na capital paulistana ela é vista como o seu oposto. O grafite é arte, a pichação sujeira, vandalismo, poluição visual. Compreendemos, contudo, as duas formas de expressão como legítimas representantes das vozes abafadas socialmente, e por isso as tratamos sem distinção.

Os artistas de rua, autores de tais inscrições, são, em sua maioria, jovens moradores de bairros periféricos de São Paulo (PEREIRA, 2010). O lugar de predileção de se manifestar desses jovens é o centro da cidade, porque esse é um ponto de convergência entre eles e também um espaço de todos. Segundo os pichadores, "dá mais IBOPE pichar no centro", isso porque todos os pichadores passariam por ali, alcançando, portanto, maior visibilidade. Vale pontuar ainda, que Pereira afirma que a relação com o espaço urbano desses jovens de periferia se altera, se movimenta: em um primeiro momento eles circulam por seus bairros, para em seguida, a partir dos grupos constituídos pelos encontros (point ${ }^{3}$ ), aventurar-se por outros bairros da cidade e, muitas vezes, o deslocamento chega ao centro da capital, que é o território mais desejado.

Ainda conforme Pereira (2010), as dinâmicas da relação com a periferia - como espaço mais geral de articulação que extravasa o bairro particular - e as regras de procedimentos relacionais afetam o próprio modo da pichação paulistana, pois, para esses jovens, sair para pichar em outras regiões da cidade é muito mais interessante do que apenas restringir-se ao seu bairro. É um momento em que inclusive deixam seus espaços e dão visibilidade, voz às periferias, imprimindo suas marcas no centro, apropriando-se de um espaço que não seria de pertencimento.

3 "O point é um espaço para fazer um rolê nas quebradas" (PEREIRA, 2010), ou seja, os jovens pichadores de reúnem para trocar experiências e aventurar-se por outros bairros. 
Como analisa Santos (2010), com a modernização contemporânea, no entanto, todos os lugares se mundializam. Mas há lugares globais simples e lugares globais complexos. Nos primeiros apenas alguns vetores da modernidade atual se instalam. Nos lugares complexos, que geralmente coincidem com as metrópoles, há a profusão de vetores: desde os que diretamente representam as lógicas hegemônicas, até os que a elas se opõem. São vetores de todas as ordens, buscando finalidades diversas, às vezes externas, mas entrelaçadas pelo espaço comum (SANTOS, 2010, p. 592). Esse espaço comum de que fala Santos nos interessa, porque é um espaço também de disputas, é um espaço de convivência conflitivo e justamente os grafites que se dirigem diretamente aos governantes exemplificam essa tensão. Existem os donos do espaço e aqueles que o ocupam mesmo sem permissão, e talvez pela insistência haja a legitimação do espaço, fazendo lembrar as ocupações por "usucapião".

Ainda, por haver em São Paulo uma diferença bem marcada entre pichadores e grafiteiros, esses últimos vêm adquirindo uma certa notoriedade e ampliando seu espaço de atuação, como se houvesse uma migração das "zonas opacas" para as "zonas luminosas". Por vezes, eles são chamados a grafitar as fachadas dos estabelecimentos comerciais como forma também de impedir a atuação dos pichadores. Além disso, especificamente no Brasil e em São Paulo, chamam a atenção os casos de utilização da pichação como publicidade e sinalização por pequenos estabelecimentos (Figura 3), como alternativa sobre os altos custos da publicidade convencional (ARRUDA, 1984, p. 61).

Figura 3: Grafite localizado na Praça da árvore, Centro de São Paulo

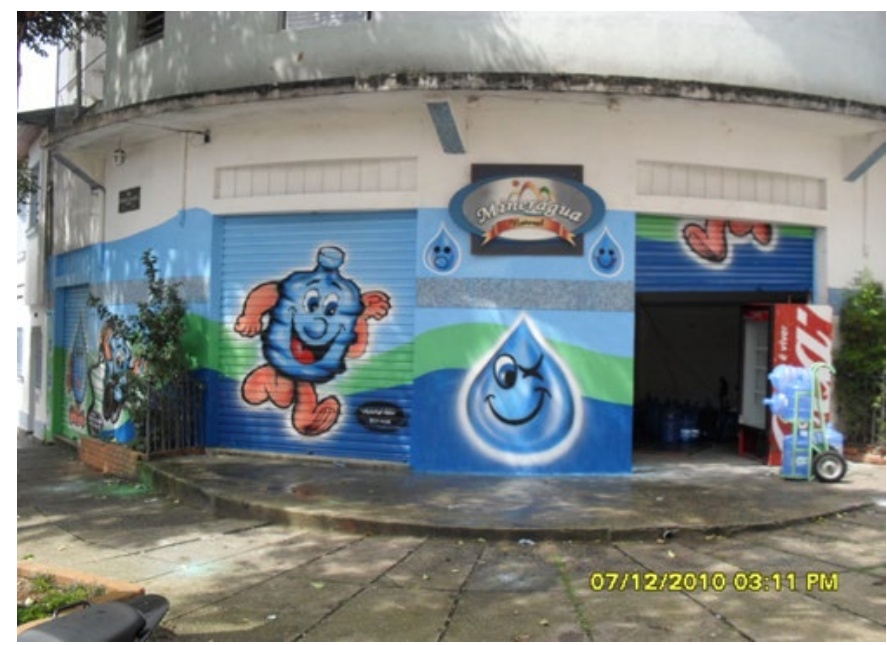

Fonte: SERVIÇO profissional de grafite. São Paulo, [ca. 2010]. Disponível em: http://www. aerografite.com.br/fotos.php?categoria=varios temas 
Outra forma de utilização do grafite que pudemos acompanhar na cidade de São Paulo recentemente, foi a manifestação política. Em julho de 2013, os jovens manifestantes lançaram mão de suas intervenções com spray, às vezes, interferindo inclusive no patrimônio público.

Figura 4: Pichação de patrimônios públicos

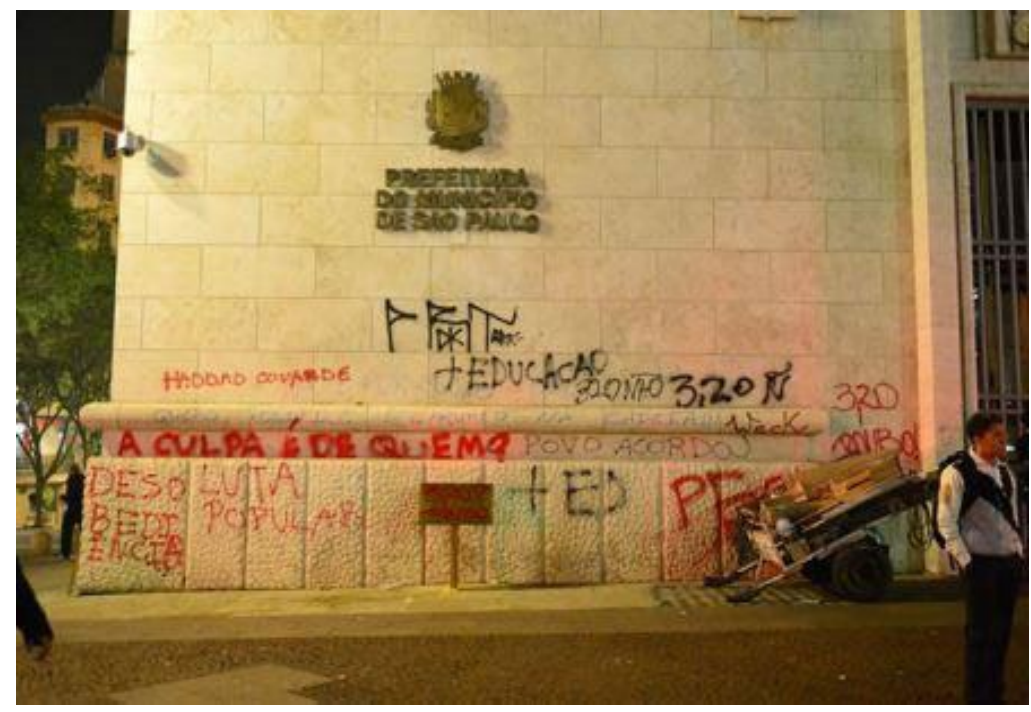

Fonte: VÂNDALOS aproveitaram manifestação na capital para saquear lojas e pichar patrimônios públicos. BuxNotícias, 20 jun. 2013. Disponível em: http://buxnoticias.blogspot.com. br/2013/06/vandalos-aproveitaram-manifestacao-na.html.

Estas são particularidades que conectam a expressão em questão e que ao mesmo tempo indicam vozes de individualidades e de coletividades, expressando ideias desvinculadas daquela programada pela metrópole: seja como uma expressão particular de um sujeito, seja como voz coletiva na expressão da pichação de protesto. Características semelhantes no que diz respeito a essa improvisação na enunciação de ideias se encontram também nas próprias técnicas dos grafiteiros, como o uso tornado comum do rolo de pintura, que estabelece a base para os desenhos (MANCO; ART; NEELON, 2005, p. 1318) (Figura 5).

Diante da diversidade das práticas do grafite na cidade de São Paulo, interessa analisar como essas inscrições urbanas ocupam a cidade e delineiam sujeitos submetidos a outros autores e atores sociais na urbe. Utilizamos, então, uma diferenciação do ator social e de sua prática. 
Figura 5: rolo para pintura

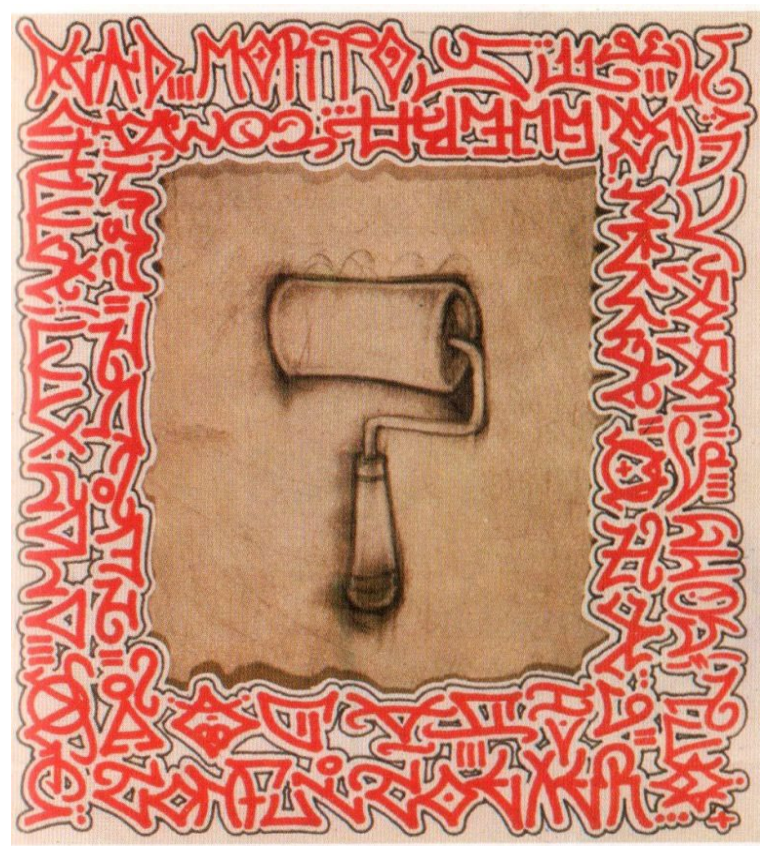

Fonte: Catálogo da exposição Barry McGee, Museu Lasar Segall, São Paulo, 1993 (apud TRISTAN MANCO; LOST ART; CALEB NEELON. Graffiti Brasil. London: Thames \& Hudson, 2005. 128 p.)

\section{Os atores e suas inscrições urbanas}

Considerando o pichador/grafiteiro como o sujeito pertencente à cultura marginal, às zonas opacas da cidade, trazemos uma segmentação que comporta esse sujeito marginal e os demais com que se relaciona.

Para o morador da periferia, onde o alcance dos governos e suas normas são menores, o que normalmente acontece, na visão desse sujeito periférico, é o abandono dos espaços e das pessoas dessa zona da cidade. Segundo Ferréz (SILVA, 2004), em texto poético sobre o aniversário de São Paulo, o morador da periferia habita outra cidade, a inexistente: "Construímos e não moramos (na cidade de São Paulo), fritamos e não comemos, assistimos, mas não vivemos, passamos vontade, mas passamos adiante". Este é o sujeito, então, marginalizado pela sociedade e que vai apropriar-se de espaços não autorizados, por meio de sua arte, desafiando as normas da mesma, já que não sente aquela cidade como dele. Seria necessário, então, torná-la um espaço comum, do que decorrem, portanto, os conflitos e tensões. 
A cidade de São Paulo é um cenário privilegiado da arte urbana, particularmente das inscrições urbanas, e por isso um exemplo singular da movimentação desses sujeitos que buscam espaços proibidos para impregnar com sua voz. Nesta cidade vão imprimir suas marcas artistas como: Alex Vallauri (um dos percursores nos anos de 1980), Os gemeos, Crânio, Zezão, Nunca, Nina, Kobra entre outros.

Tendo como referência essa problemática, a pichação e o grafite na cidade de São Paulo podem também ser pensados por meio das palavras do artista Otávio Pandolfo, da dupla "Os gemeos", "se você não utilizar a cidade, ela vai utilizar você", em entrevista concedida à revista do Cambuci (COLECIONADOR, 2009). Da linguagem espontânea do grafiteiro é possível extrair dados sobre como esta arte se relaciona com o espaço urbano, estabelecendo relações de tensão e relaxamento no seu processo de produção e, decorrente desse fazer, a cidade se reveste de uma nova narrativa que altera o percurso "programado" por aqueles que a organizam, instaurando novas narrativas nos espaços cinza. O grafite, portanto, é a arte da apropriação do espaço urbano, uma prática além da programação citadina. Uma arte de conflito, de ocupação e busca de pertencimento.

Insistimos que a pichação e o grafite não são artes legitimadas, elas se impõem, visibilizam-se e aos poucos conquistam espaço, e como consequência, se veem reconhecidas. Estão longe dos cânones artísticos, que de certa forma elitizam a contemplação, encerrando a arte em museus e galerias para poucos iniciados. A inscrição urbana está na rua para ser fruída, alterada, transformada pelo cidadão. Entendemos o grafiteiro como um agente social que atua e transforma a paisagem urbana e essa arte como forma de democratização da expressão plástica.

Nas tramas urbanas, o grafite ou o seu agente saem da periferia e apropriam-se de todo o espaço da cidade. O grafite, de certa maneira, "liga" as dimensões centrais e as periféricas que constituem a cidade.

Quando o sujeito ultrapassa a fronteira, os limites pré-estabelecidos, ele seria o próprio discurso do sujeito marginalizado; há a assunção de uma voz anteriormente abafada, mas que se lança ao sol, ao vento. Quando a dupla Osgemeos utiliza a metáfora de personagens que ultrapassam muros, de alguma maneira descreve esta situação (Figura 6).

$\mathrm{Na}$ arte que ocupa a cidade, os atores sociais são outros. Um resultado disso são os pixos/grafites com temas de denúncia social. Um exemplo seria o grafiteiro Cranio, que criou um personagem índio, o qual perambula pela cidade de São Paulo refletindo decadência e sofrimento. Um índio aculturado que grita pelo Brasil, pela cidade de São Paulo. Inicialmente esse artista imprimiu 
sua expressão no bairro onde vivia, o Tucuruvi, passando em seguida a ocupar toda a cidade com sua denúncia de um Brasil (São Paulo) vendido ou à venda (Figura 7).

Figura 6: personagens que ultrapassam muros

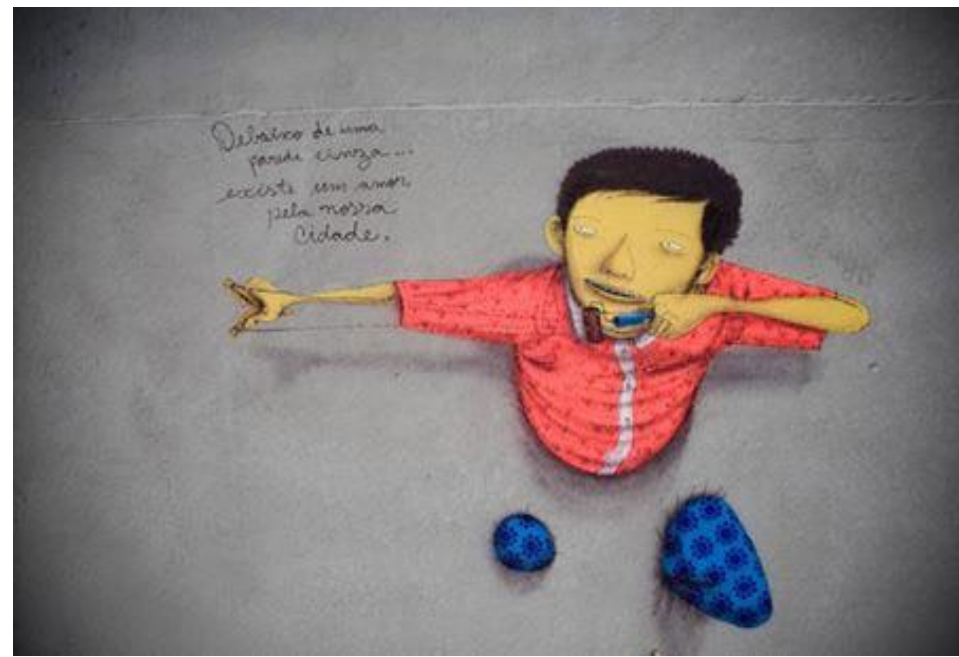

Fonte: WARHOLITOS. Cultura para niños. Recomendación. Os gemeos. [S.l., s/d] [ca. 2013]. Disponível em: https://warholitos.wordpress.com/2012/10/05/recomendacion-os-gemeos/.

Figura 7: Índio

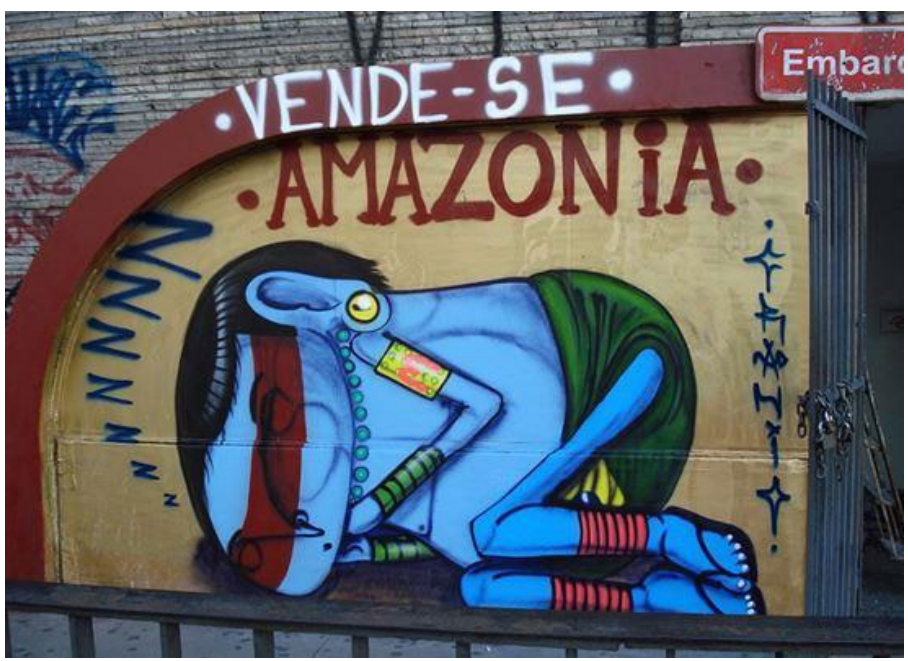

Fonte: Fábio de Oliveira (Crânio). CAVALERA blog. 18 nov. 2014. Disponível em: $<$ http:// www.cavalera.com.br/blog/tag/street-art/ 
Ou ainda, um ator social que é mais rejeitado por todo esse sistema impositivo da cidade, aquele que transgrede acintosamente as normas. Talvez pudéssemos identificar este sujeito como aquele que pula muros, desafia policiais e invade a cidade para ver sua voz imprimida nela, independente dos riscos (Figura 8). Em outras palavras, é o sujeito que viola os códigos deste destinador, sendo então perseguido, não importando se sua ação tinha por objetivo delimitar territórios ou declarar uma indignação. Em ambos os casos, recai a mesma etiquetação.

Figura 8: Pichações em monumentos

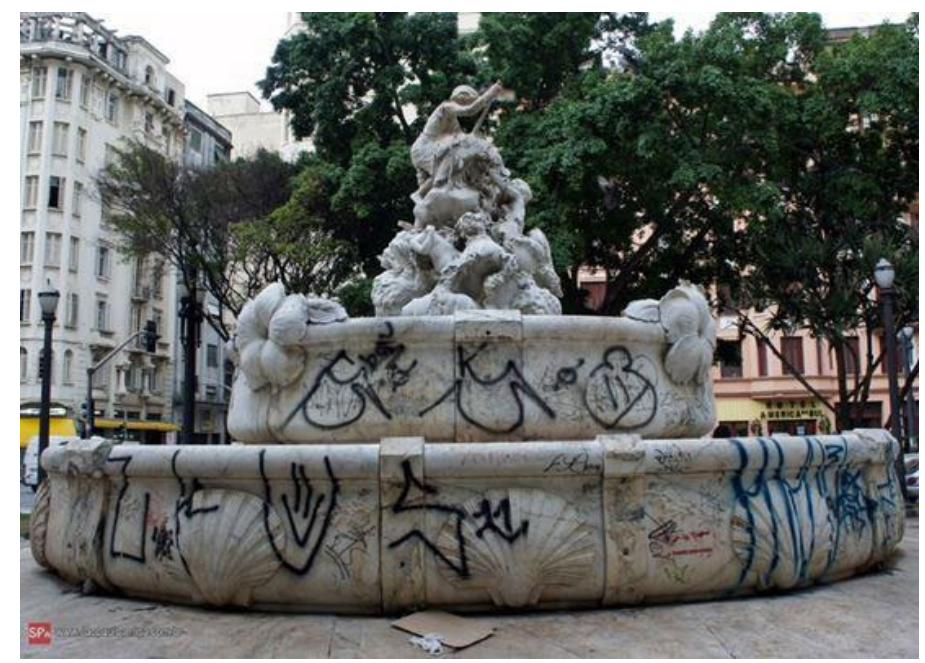

Fonte: Douglas Nascimento. São Paulo antiga. GARCIA, Glaucia. O monumento que a prefeitura de São Paulo abandonou. São Paulo, 19 dez., 2011. Disponível em: http://www. saopauloantiga.com.br/o-monumento-que-a-prefeitura-de-sao-paulo-abandonou.

Outra forma de expressão, essa autorizada, pode ser exemplificada como um movimento oposto ao do grafiteiro, indo do centro à periferia, ou mesmo um movimento daquele que transforma periferias em centros em detrimento de seus habitantes, culturas e vivências originais (COTRIM, 2014, p. 186-203). Essas ações são marcadas como legais e confirmadas perante a lei, considerando que devem estar primeiramente inseridas nas normas sociais. São práticas que se dão, também de forma inversamente oposta, na invisibilidade, sendo percebidas apenas pelos sujeitos afetados. Em relação ao grafite, é possível pensar sobre as propagandas políticas em época de eleições, quando os sujeitos do centro buscam votos nos bairros periféricos e para isso se apropriam dos muros dos bairros em detrimento da população. Outro exemplo desse tipo de prática viria de estabelecimentos de serviços públicos, como escolas, que 
para ver seus muros livres de pichações inconvenientes, desenham paisagens geralmente descontextualizadas em relação à região (Figuras 9 e 10).

Figura 9: Projeto fotográfico Voto em Imagens

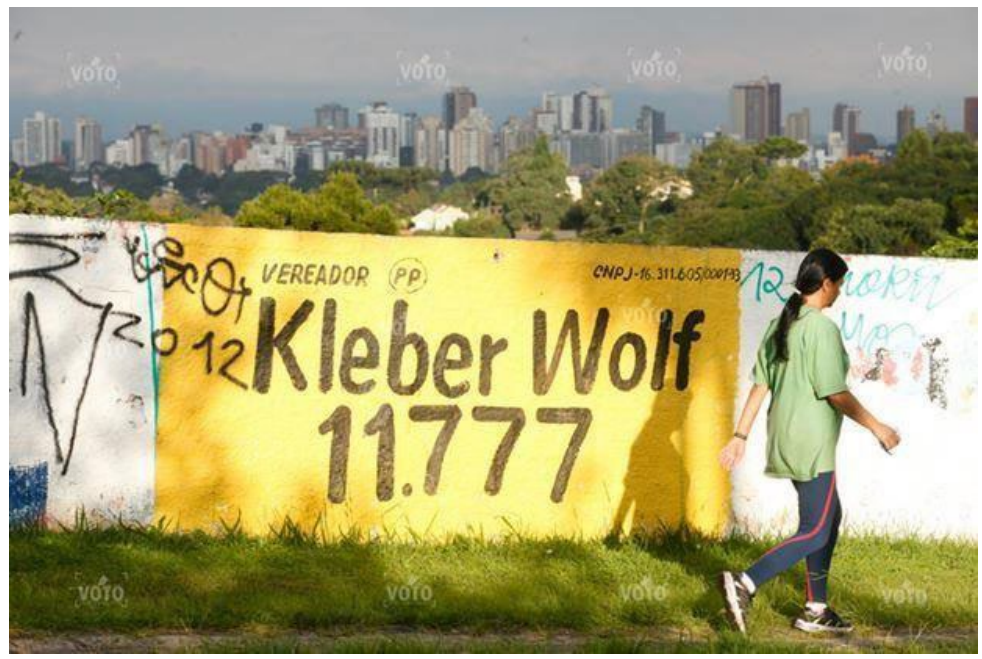

Fonte: André Rodrigues. PROJETO fotográfico Voto em Imagens. [ca. 2013]. Disponível em: https://votoemimagens.wordpress.com/tag/pichacao/.

Figura 10: Muros de escolas municipais

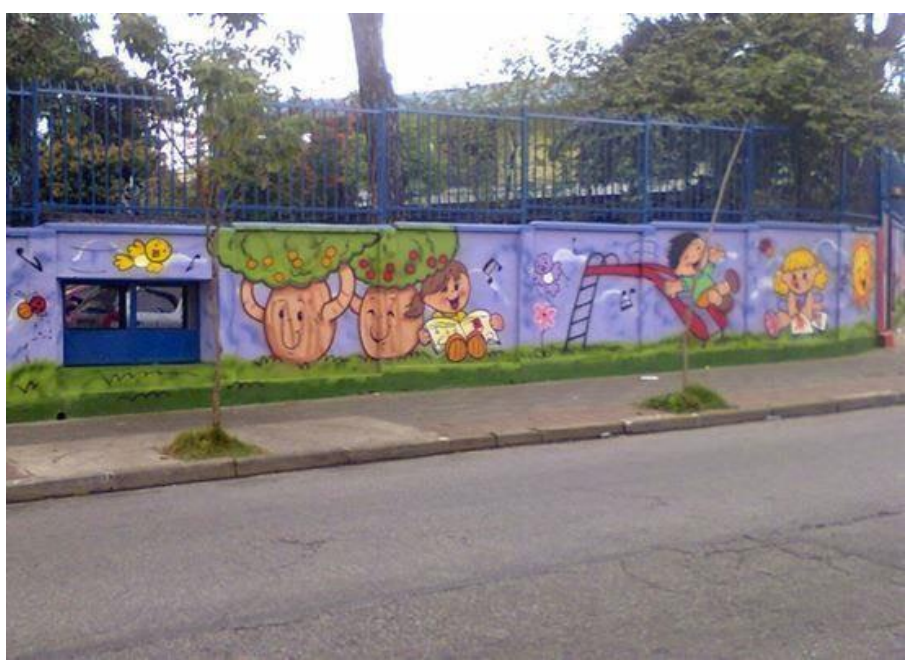

Fonte: WILL Arte Graffiti. Muros de Escolas Municipais. [S.1., s/d]. [ca. 2010]. Disponível em: http://willarte.blogspot.com.br/p/muros-de-escolas-municipais.html. 
A arte urbana, posto que compartilha da condição de linguagem urbana, quebra o paradigma da rotina da cidade. É uma arte dotada de um "fazer" circunscrito ao contexto espacial e temporal em que vivemos. Ou seja, a limitação visual corriqueira que a cidade transmite em seus textos, como na sinalização de trânsito (SILVEIRA, 2010) é rompida com as mensagens do grafite. Isto também ocorre com quaisquer formas artísticas visuais, incluindo a arquitetura e o design, embora aqui nos concentremos no grafite enquanto representante expressivo da cultura do sujeito "marginal" e muitas vezes não autorizado, as demais são oficializadas. Além disso, não existem os indicativos dessa arte; ao contrário do sujeito que vai ao museu ou galeria com uma boa noção do que vai encontrar, as inscrições urbanas não avisam os usuários da cidade, é um acontecimento a ser digerido. Ela desponta do meio e de dentro da rotina funcional como um discurso geralmente não esperado (Figura 11). Mesmo nos casos em que há autorização, a conexão com as culturas das periferias, marginalizadas dentro do sistema estabelecido nas cidades, permanece. Principalmente em seus temas, utilizando muitas vezes a metalinguagem.

Figura 11: Osgemeos - estação Lapa

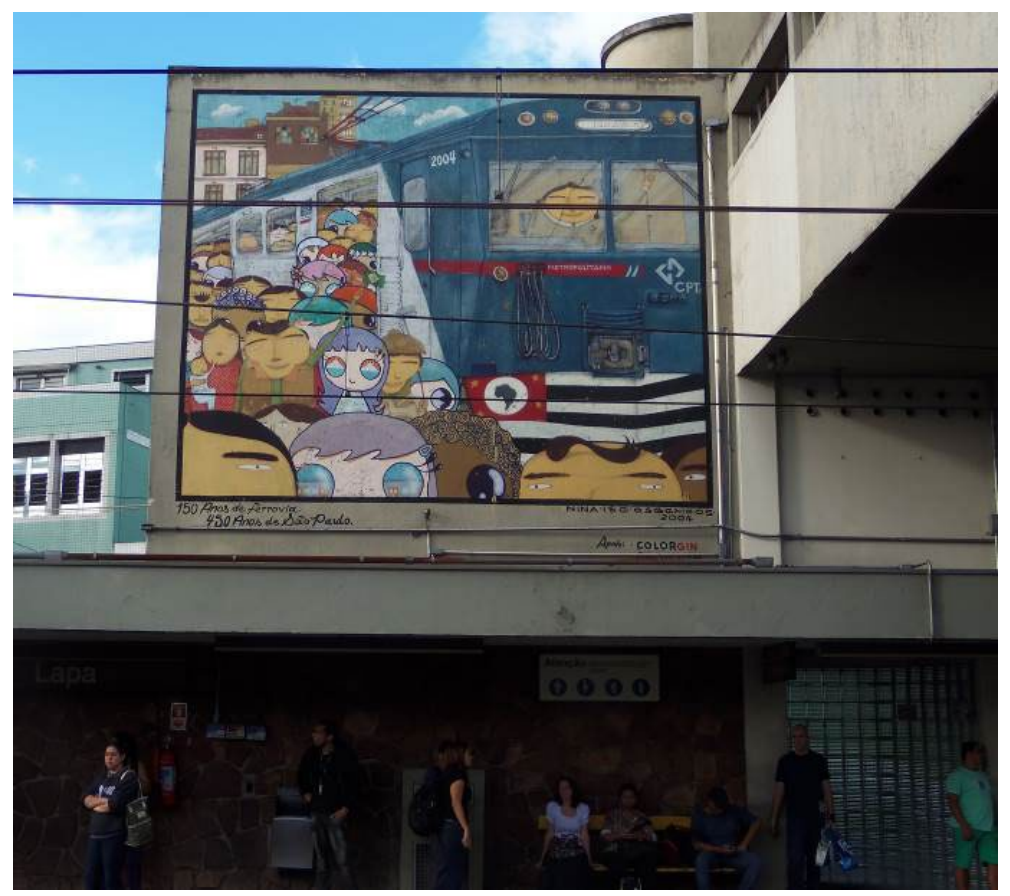

Fonte: Imagem coletada pelos autores (2015) 


\title{
Considerações finais
}

Podemos perceber que há duas relações complexas e divergentes no programa dos espaços urbanos da cidade de São Paulo. A primeira diz respeito à aprovação ou não do destinador oficial da cidade, responsável pela programação da mesma. Seu contrato com os usuários da cidade não inclui a participação desses como agentes de transformação, principalmente em discursos que fujam à programação prescrita. Ao mesmo tempo, dá-se a diferenciação entre as partes centrais e periféricas da cidade por meio das próprias manipulações inerentes desse sistema, como a decretação dos valores de imóveis, etc.. Sob o viés dessa primeira tensão, em relação à periferia enquanto ponto originário do grafite, aponta Migliano (2013, p. 13):

\begin{abstract}
Esse outro lugar de produção de subjetividade que funciona sem o capital especulativo financeiro agenciar os seus desejos e políticas, acaba sendo uma característica comum aos modos de praticar graffitis, que resistem criando em oposição aos poderes da hegemonia cultural e midiática, atrelada aos processos de espetacularização urbana.
\end{abstract}

Como descrito ao longo do artigo, há aqueles que têm voz e os que não têm voz, como se a cidade também fosse gerida por apenas uma parcela da população.

Já pela segunda relação, tem-se uma busca de ligação entre essas partes que sofreram diferenciação na cidade, os centros e as periferias. No desenrolar dos discursos que a representam, porém, torna-se necessário utilizar uma forma que não é aceita pelo destinador da cidade. Neste tipo de discurso existe o risco, a transgressão e de certa forma também a imposição de um certo discurso que quer tornar-se visível.

Muitas vezes atuam duas forças divergentes: aquela que acusa e denuncia e aquela sanção em que a população em geral aceita o grafite e a arte urbana. Isso pode ser percebido, por exemplo, no documentário $\mathrm{Ci}$ dade Cinza (2013), em que os agentes municipais não cobrem todas as paredes pintadas que encontram, mas selecionam aquelas que serão apagadas. Vale lembrar que a aceitação da população foi gradual e aconteceu na medida em que os artistas propunham novas narrativas e que o usuário da cidade ia encontrando sentido em tal inscrição. Por isso, como discutido no artigo, na cidade de São Paulo existem ao menos duas formas de inscrição reconhecida: o grafite - bem aceito, e a pichação - ainda mal vista. Esse é sempre um procedimento subjetivo, mas que indica um princípio de interação entre o destinador da cidade e sua população, seja ela o agente 
da inscrição, seja apenas o observador da prática. Esquematicamente poderíamos indicar:

\begin{tabular}{l|lll} 
Enunciados: & Destinador da cidade & vs & Destinador outro \\
\cline { 2 - 4 } & $\frac{\text { População central }}{\text { População periférica }}$ & & População central = População periférica
\end{tabular}

Fonte: elaborado pelos autores.

Como definir esse destinador outro? Ele é a própria população como um todo, em faíscas de discurso que despontam desse todo. Cada faísca traz um discurso próprio que não deixa de ser também o discurso de outros. Inclusive a pichação que demarca territórios, pois quando se diz "o outro" generaliza-se uma grande multiplicidade.

A forma como a cidade é distribuída espacialmente, e axiologicamente, não é uma homologação decorrente do contrato com esse destinador, mas com o destinador da programação da cidade, normalmente autoritário e que representa uma pequena parcela da população, e que quase nunca escuta as vozes e desejos dos marginalizados. Voltamos ao artigo de Ferréz (SILVA, 2004) em que ele divide a cidade:

Pode-se dizer que a cidade é subdividida em duas, e isso é claro,
central e periférica, a parte difícil é dizer quem cerca quem.

Que os moradores da periferia (como eu, tá ligado?) vão ao centro para prestar serviço não é nenhuma novidade, mas e a diversão? E desfrutar a cidade? Aí são outros quinhentos, ou melhor, são outros 450 .

De acordo com o conflito descrito, os muros e paredes são fronteiras entre externo e interno, aberto e fechado. O sujeito que pinta se posiciona (ou é posicionado) nesta fronteira, pelo lado de fora. Com isso vemos dois caminhos diferentes que apontam para uma mesma dualidade, a oposição entre governar e governar-se, e também em atuar como agente social com participação em uma destinação coletiva ou ser apenas um usuário sem voz da metrópole. Posto isso, as palavras de Santos corroboram as análises apresentadas e fazem pensar sobre as diversas formas de ocupação espacial, social e cultural: 
O lugar é o quadro de uma referência pragmática ao mundo, do qual lhe vêm solicitações e ordens precisas de ações condicionadas, mas é também o teatro insubstituível das paixões humanas, responsáveis, através da ação comunicativa, pelas mais diversas manifestações da espontaneidade e da criatividade. $(2010$, p. 592)

\section{Referências}

ARRUDA, V. Um spray na mão e uma ideia na cabeça. Arte em revista, São Paulo, Ano 6, n. 8, p. 59-63, out. 1984 .

ASSOCIAÇÃO viva o centro. Disponível em: http://www.vivaocentro.org.br/curta-o-centro/ como-chegar-ao-centro.aspx. Acesso em: 09 fev. 2015.

BORGES, L. A. Entre o desejo e a morte. Arte em revista, São Paulo, Ano 6, n. 8, p. 64-68, Out. 1984.

CAVALERA blog. 18 nov. 2014. Disponível em: http://www.cavalera.com.br/blog/tag/street-art/. Acesso em: 09 fev. 2015.

CERTEAU, Michel de. A invenção do cotidiano. Petrópolis: Vozes, 2004.

CIDADE cinza. Direção: Guilherme Valiengo, Marcelo Mesquita. Produção: Peppe Siffredi. São Paulo: SALA12 Filmes, 2013.

COLECIONADOR de vidas. Os gêmeos//Grafiteiros//The twins//Graffiti. 26 out. 2009. Disponível em: https://www.youtube.com/watch?v=-XLrae8FcP8. Acesso em: 09 fev. 2015.

COTRIM, L. R. Pontes Estaiada - construção de sentidos para São Paulo. São Paulo: Estação das Letras e Cores Editora, 2014.

GARCIA, G. O monumento que a prefeitura de São Paulo abandonou. São Paulo antiga, São Paulo, 19 dez. 2011. Disponível em: http://www.saopauloantiga.com.br/o-monumento-que-a -prefeitura-de-sao-paulo-abandonou. Acesso em: 09 fev. 2015.

KOBRA. Muros da memória. Disponível em: http://eduardokobra.com/muro-de-memorias/. Acesso em: 09 fev. 2015.

LANDOWSKI, E. Jogos Ópticos: situações e posições da comunicação. In: A Sociedade Refletida. São Paulo: EDUC-Pontes, 1992.

LANDOWSKI, E. Presenças do outro. São Paulo: Perspectiva, 2002.

LANDOWSKI, E. Les Interactions Risquées. Limoges: Pulim, 2006.

MACHADO, A. Brás, Bexiga e Barra Funda. Artigo de Fundo (sem numeração de página). São Paulo: Moderna, 1999. 
MANCO, T.; ART, L.; NEELON, C. Graffiti Brasil. Londres: Thames \& Hudson, 2005.

MIGLIANO, M. Mapa dos Graffitis de Belo Horizonte: apropriações da rua e da internet. In: CONGRESSO INTERNACIONAL EM COMUNICAÇÃO E CONSUMO, 3, São Paulo. Anais... São Paulo, 2013. Disponível em: http://www.espm.br/download/Anais_Comunicon_2013/Comunicon.swf. Acesso em: 08 fev. 2015.

PEREIRA, A. B. As marcas da cidade: a dinâmica da pixação em São Paulo. Lua Nova: Revista de Cultura e Política, São Paulo, 79, 2010. Disponível em: http://www.scielo.br/pdf/ln/n79/ a07n79.pdf. Acesso em: 08 fev. 2015.

OSGEMEOS protestam contra prefeitura de SP após grafite apagado. Portal Rua Augusta, São Paulo, 2013. Disponível em: http://augustasp.com/ruaaugusta/05/osgemeos-protestam-contra -prefeitura-de-sp-apos-grafite-apagado/. Acesso em: 08 fev. 2015.

PICHAÇÃO. Disponível em: http://www.pichacao.com. Acesso em: 08 fev. 2015.

PROJETO fotográfico voto em imagens. Disponível em: https://votoemimagens.wordpress. com/tag/pichacao/. Acesso em: 09 fev. 2015.

SANTOS, M. O lugar e o cotidiano. In: SANTOS, B. de; MENESES, M. P. (Orgs.). Epistemologias do Sul. São Paulo: Cortez, 2010.

SERVIÇO profissional de grafite. Disponível em: http://www.aerografite.com.br/fotos.php?categoria=varios temas. Acesso em: 5/2/2015.

SILVA, R. F. S. da. Sobreviver em São Paulo. Folha de S. Paulo, São Paulo, 24 jan. 2004. Opinião. Disponível em: http://www1.folha.uol.com.br/fsp/opiniao/fz2401200410.htm. Acesso em: 05 fev. 2015.

SILVEIRA, Fabricio. O parque dos objetos mortos. Porto Alegre: Armazem Digital, 2010.

VÂNDALOS aproveitaram manifestação na capital para saquear lojas e pichar patrimônios públicos. BuxNotícias, 20 jun. 2013. Disponível em: http://buxnoticias.blogspot.com.br/2013/06/ vandalos-aproveitaram-manifestacao-na.html. Acesso em: 9 fev. 2015.

WARHOLITOS. Cultura para niños. Disponível em:

https://warholitos.wordpress.com/2012/10/05/recomendacion-os-gemeos/. Acesso em: 9 fev. 2015.

WILL arte graffiti. Disponível em: http://willarte.blogspot.com.br/p/muros-de-escolas-municipais.html. Acesso em: 9 fev. 2015.

Submissão em: 10/02/2015

Revisão em: 28/11/2015

Aceite em: 13/04/2015

Rafael Giardini Lenzi é pesquisador científico na área de comunicação sob a teoria da semiótica discursiva e da sociossemiótica. Principais áreas de atividade: ensino e 
pesquisa, tradução, comunicação, publicidade e propaganda.

E-mail: lenzirafael@yahoo.com.br

Mariana Cortez é professora Adjunto I, Português Língua Adicional, Universidade Federal da Integração Latino-americana. Foi leitora do Brasil junto à Universidad Nacional de Córdoba, Argentina (UNC - Facultad de Lenguas), designada pelo Ministério de Relações Exteriores do Brasil e por processo seletivo CAPES. Professora do Seminário de Literatura Infantil e Juvenil no curso Profesorado de Portugués. Desenvolve e coordena o Curso de Português para filhos de brasileiros residentes na Argentina - Língua portuguesa como língua de herança- projeto proposto pelo Consulado Geral do Brasil em Córdoba e professora do Curso de Pós-Graduação Portugués lengua extranjera: sistematización de acciones comunicativas en el ámbito académico, na Universidad Nacional de Río Cuarto (UNRC). Doutora em Letras pela Universidade de São Paulo (2008), projeto fomentado com bolsa sanduíche (CAPES) - estágio de doutorado no exterior, Portugal (UTAD). Mestre em Semiótica e Linguística Geral (2001) pela Universidade de São Paulo. E-mail: marianacortez1674@gmail.com 